\title{
Organochlorine Pesticides Residues in Mussels of Greek Island Evia
}

\author{
Konstantinos M. Kasiotis (Corresponding author) \\ Laboratory of Pesticides Toxicology, Benaki Phytopathological Institute \\ 8 St. Delta Street, PO box 14561, Athens, Kifissia, Greece
}

Tel: 30-210-818-0384 E-mail: K.Kasiotis@bpi.gr

\begin{abstract}
A simple and effective analytical procedure was developed for the determination of some organochlorine residues in mussel samples of two sampling points in Evia Island, Greece. The sample extraction was performed on lyophilized samples using either the Microwave Assisted Solvent Extraction (MASE) or the Soxhlet extraction technique. Using both techniques aldrin, endrin and endosulfan sulfate were determined. The quantification of these pesticides was carried out by Gas Chromatography-Mass Spectrometry (GC-MS) working in the Selected Ion Monitoring (SIM) mode and the recoveries ranged from 75 to $102 \%$ at two spiking levels for 6 replicates.
\end{abstract}

Keywords: Organochlorine pesticides, GC-MS, Mussels, Microwave, Soxhlet, SIM mode

\section{Introduction}

The outburst of technological development and the continuously increasing population have resulted in enlarged production of basic agricultural products whose production and provision is associated with chemicals of organic origin applicable in cultivation. The latter, which is a result of human activities on land, are very persistent, and through the aquifer, end up into the aquatic environment. Persistent Organic Pollutants (POPs) are compounds that resist photochemical, biological and chemical degradation (Eduljee, G. H., Kanan et. al 1994, Parimi et. al 2006). As hydrophobic compounds they display high affinity for lipids and a tendency to accumulate in marine organisms. Consequently, they bio-accumulate through the food chain causing damages to the human health and environment.

Organochlorine Pesticides (OCPs) are synthetic compounds which are common pollutants in coastal areas and estuaries (Perugini et. al 2004, Khaled et. al 2004). Their presence -including their metabolites- is of great importance since they are related to chronic adverse effects on both humans and wildlife. Despite the banning of PolyChlorinated Biphenyls (PCBs) and DichloroDiphenylTrichloroethanes (DDTs) since the early 1970s, in many countries (including Greece) these compounds are still found in analyses performed in various matrices, indicating either that they are still applied, or the fact that they are quite stable and persistent in many kinds of environmental media.

Organisms of aquatic environments can serve as typical media for the assessment of marine pollution. Previous studies have pointed to the usefulness of mussels as geographic bioindicators of chemical contamination. Therefore, they continue to be analyzed for the monitoring of marine environment pollution (Kurt, P.B., Ozkoc, H.B. 2004). In Greece, mussels are the only shellfish bred in large quantities. Mussels (Mytilus Galloprovincialis) have been used as biomarkers for the assessment of heavy metals' pollution in coastal areas (Vlahogianni et. al 2007, Richardson et. al 2008). Moreover, as it has been previously mentioned, several studies have shown that organic contaminants, such as OCPs, tend to accumulate in mussels tissues (Ozkoc et. al 2007). As a result, the estimation of the levels of OCPs can conceivably provide us either with valuable information regarding the pollution of the aquatic environment or possible human being exposure through dietary intake.

The marine environment in Evia is a characteristic example for the plethora of aquatic organisms. Although the 95\% of mussels are bred in Northern Greece (Batzios et. al 2004), Evia still holds a significant position among Greece's top quality indigenous environments for bivalves, either in marine farm companies or by mere fishing. Nevertheless knowledge of the occurrence of OCPs compounds in the Evia's coastal area is extremely limited. Western and Central Evia are possibly affected by the sewage dumping of Chalkida, the capital of the island. Industrial waste spread throughout the island and shipping related pollution can possibly affect the coastal area. The latter, which is in 
opposition to the continental Greece, can indirectly be influenced from the sewage and industrial waste that originate from the metropolitan region of adjacent Attica.

For the analysis purposes, an extraction with organic solvents takes place, and then a cleanup step, column fractionation and Gas Chromatography coupled with various detectors such as Mass Spectrometer or electron capture detector (GC-ECD). Liquid Chromatography Mass Spectrometry (LC-MS) has also been used as means for the determination and quantification of toxins in Greek Mussels (Mytilus Galloprovincialis) (Ciminiello et. al 2006).

\section{Materials and Methods}

\subsection{Study Area and Sampling Points}

This study focused on the analysis of indigenous mussels cultured on the island of Evia, Greece (Figure 1). This region is known for the bivalves' productions in which mussels (Mytilus Galloprovincialis) are included.

Mussels (M. galloprovincialis, 6-7 cm shell length), never before being exposed to growth stimulants, were collected $(1 / 2 \mathrm{~kg})$ at Karystos in Southwest Evia island during September 2008. The second sample $(1 / 2 \mathrm{~kg})$ of $M$. galloprovincialis was collected in the territory of Orei at Northwest Evia during September 2008. Thus, neither of the samples was collected from territories near Chalkida city. This was decided on the basis of assessment of mussels' pollution away from a possibly highly affected area, since Chalkida and its surroundings have an active industrial zone and a plethora of agricultural activities.

Immediately after collection, mussels were transferred fresh into an ice cool box to the laboratory where they were dissected. After sucking the whole soft tissues of mussels from the two locations, they were pooled, homogenized, transferred to beakers and lyophilized. The resultant reddish-brown powder was further analyzed.

\subsection{Reagents and Materials}

Organochlorine pesticides standard solutions for aldrin, endrin, dieldrin, $\alpha$-endosulfan, $\beta$-endosulfan and endosulfan sulfate were prepared from the respective standards purchased from Supelco (Bellefonte, PA, USA). All solvents used were pesticide residue analysis grade from Merck (Darmstadt, Germany).

\subsection{Soxhlet Extraction}

The approach of extracting organic compounds from various matrices with Soxhlet apparatus is popular within toxicologists who are involved in the identification of toxic substances in biological organisms or plants. In this context, $7 \mathrm{~g}$ of lyophilized mussels were placed with equal amount of sodium sulfate at the bottom of the Soxhlet apparatus covered above with glass wool. The solvent of choice was $n$-hexane $(200 \mathrm{~mL})$ and the extraction time was 6 hours. After the extraction the solvent was removed in vacuum and the mixture was reconstituted with hexane, SPE filtered and eluted directly to the gas chromatograph mass spectrometer (GC-MS).

\subsection{Microwave-Assisted Solvent Extraction (MASE)}

Microwave assisted extraction is a time and cost effective way of extracting valuable compounds from lyophilized or non lyophilized biological samples (García et. al 2008). In this case the mussels were homogenized, lyophilized and then placed in a specific Teflon vessel used in the microwave extractor apparatus (CEM Corporation, MARS microwave extractor). The solvent of choice was $n$-hexane $(60 \mathrm{~mL})$ and it was applied to $2.1 \mathrm{~g}$ of lyophilized mussels in order to be comparable with the amounts used in the Soxhlet extraction. Equal volume of $n$-hexane was placed in an anti-parallel vessel into the extractor. The program used in the latter extraction is the following: Functioning of MARS extractor at 800 Watt, with gradual increase of temperature reaching $100^{\circ} \mathrm{C}$ in $10 \mathrm{~min}$, and staying at that temperature for 15 min. A subsequent cool down period of 5 min was applied. By prolongation of the time of MASE extraction it was not obtained higher concentration of the compounds analyzed.

\subsection{Solid Phase Extraction (SPE) - Purification}

SPE was applied prior to the injection to the GC-MS system. For this purpose an IST VacMaster apparatus was used with the appropriate vacuum pump and the respective Florisil SPE cartridges (Waters, SEP-PAK ${ }^{\circledR}$ Cartridges). Three fractions were collected after elution with hexane, hexane/dichloromethane 5:5 and pure dichloromethane in equal volumes $(5 \mathrm{~mL})$ in order to extract compounds of variable polarity. Aldrin was identified in the hexane fraction, endrin and dieldrin in the hexane/dichloromethane fraction. As far as the endosulfan group is concerned, endosulfan-a was collected from the second fraction while endosulfan-b and endoslfan sulfate from the dichloromethane fraction. The extracts were evaporated by a gentle stream of nitrogen until the volume of $2 \mathrm{ml}$.

\subsection{Gas Chromatographic Conditions}

Analysis was carried out on an Agilent 6890N chromatograph equipped with a split-splitless injector and a 5975B inert XL EI/CI MSD (Agilent Technologies) connected to MSDChemStation G1701 DA MSD software, version D.03.00.611. The capillary column was a DB-5MS $(30 \mathrm{~m} \times 0.25 \mathrm{~mm} \times 1.0 \mu \mathrm{m})$ with $5 \%$ diphenyl $-95 \%$ dimethylsiloxane. The injector and detector were operated at $300^{\circ} \mathrm{C}$ and $280^{\circ} \mathrm{C}$, respectively. The sample $(1 \mu \mathrm{L})$ was injected into the pulsed splitless 
mode and the oven temperature was programmed as follows: $100{ }^{\circ} \mathrm{C}$ for $2 \mathrm{~min}$, raised to $180^{\circ} \mathrm{C}\left(15^{\circ} \mathrm{C} / \mathrm{min}\right)$, raised to $240^{\circ} \mathrm{C}\left(3^{\circ} \mathrm{C} / \mathrm{min}\right)$, raised to $285^{\circ} \mathrm{C}\left(10^{\circ} \mathrm{C} / \mathrm{min}\right)$ for $10 \mathrm{~min}$. Helium was the carrier gas $(1.8 \mathrm{~mL} / \mathrm{min})$ and nitrogen $(30$ $\mathrm{mL} / \mathrm{min}$ ) the make-up gas.

\section{Results and Discussion}

\subsection{Validation of the Analytical Method}

The linear dynamic range, recovery, precision, limits of detection (LOD) and quantification (LOQ) were established for the validation of the developed analytical method. For the linear dynamic range, the calibration samples were prepared using appropriate dilution of the stock aldrin, endrin, dieldrin, $\alpha$-endosulfan, $\beta$-endosulfan and endosulfan sulphate (stock solutions of $100 \mathrm{ppm}$ for each pesticide) solutions in $n$-hexane. Five concentration levels were studied with 3 replicates at each level. Good linearity of the response was found at specific concentration range indicated in Table 1 , with the respective correlation coefficient $\left(\mathrm{r}^{2}\right)$ for each pesticide.

\subsection{Limit of Detection - Limit of Quantification, Precision}

The LOD and LOQ were determined via statistical calculations using calibration plots established at concentration levels close to the expected LOD. The LOD was defined as 3.3(Sy/x)/a and the LOQ as $10(S y / x) / a$, where $S y / x$ represents the residual standard deviation and $a$ is the slope of the calibration plot. Thus, retention time, LOD, LOQ and the respective $\mathrm{m} / \mathrm{z}$ monitored in the SIM mode are depicted in Table 2.

Recovery was assessed using spiked mussel samples at two concentration levels. The recovery of each active substance from the matrix was the main criteria for quantitative quality control of the analytical results of the present work. The recovery was studied in the laboratory as part of the method validation. The applied analytical method for the determination of aldrin, endrin and endosulfan sulfate covered the needs of the present study. Satisfactory results were obtained for all levels with recoveries for low and high concentrations, well above the cut off value of 70\%. RSD's for both low and high concentrations were $<5 \%$. The precision of the method was studied by measuring the repeatability (intra-day) and reproducibility (inter-day) of the results obtained. For repeatability studies, five analyses of standard spiked mussels samples were successively analyzed in 1 day (Table 3 ). The inter-day precision was tested by analysis of standard-spiked mussels samples (Table 3 ) for five consecutive days.

The obtained RSD values are depicted in Table 3 and ranged from $4.8 \%$ to $9.2 \%$ (intra-day precision) and from $5.3 \%$ to $11.1 \%$ for inter-day precision (as expected since the RSD values for inter-day precision are usually higher than the ones of intra-day) - for all analytes - confirming the satisfactory performance of the methodology developed in this work.

\subsection{Analysis}

In Table 4 the concentrations of the pesticides found are depicted. Aldrin and endrin were detected by both MASE and Soxhlet technique with concentrations above the corresponding LOD. Endosulfan sulphate was also detected when both techniques were employed. Furthermore traces of dieldrin were detected by MASE extraction in the sample of Orei region however they were below the corresponding LOD and thus not quantified. Figure 2 shows the magnified $\mathrm{GC}$-chromatogram of the area where aldrin is eluted and in Figure 3 the respective $\mathrm{m} / \mathrm{z}$ ratios for aldrin. The chemical structure of the fragment ions of the selected pesticides are an outcome of ionization, successive chlorine loss and sometimes ring saturation. A characteristic fragment of aldrin is the one which corresponds to the loss of two chlorine atoms and one hydrogen atom to form the [M-2Cl-H] fragment at 293 (m/z value). Moreover the typical fragment at $263\left(\mathrm{~m} / \mathrm{z}\right.$ value) corresponds in the case of endrin to $\mathrm{C}_{7} \mathrm{H}_{3} \mathrm{Cl}_{5}$. This fragment also appears in the case of aldrin and dieldrin. For endosulfan sulphate the base peak is $\mathrm{m} / \mathrm{z} 387$ and represents the loss of $\mathrm{HCl}$ group from the molecular ion.

The confirmation of the aldrin existence was achieved by spiking with aldrin the vial with the real mussel sample. The increase in the abundance of aldrin peak at the same retention time indicated the aldrin presence in the Karystos sample (Figure 4 and 5). By following the same procedures endrin and endosulfan sulphate were detected and quantified.

\subsection{Levels of Organochlorine Pesticides-Comparison with Similar Matrices at Different Sampling Points}

In the whole Mediterranean Sea, the bivalve Mytilus galloprovincialis and the red mullet (Mullus sp.) have been immensely studied reflecting the contamination which can be attributed to the land based origin (sediment). The findings of this research can be compared with the mussel watch survey which was conducted in 1973/1974 and 1988-1989 along the Mediterranean Coast of France and Italy by Villeneuve et. al (1999), between Sete and Genoa. In this research it was found that concentrations of DDTs were the highest ranging from 20 to $630 \mathrm{ng} \mathrm{g}^{-1}$ (dry wt.).

Traces of dieldrin which were found in our case are less than the concentration findings of Villeneuve et. al (1.8-36 ng $\mathrm{g}^{-1}$ dry wt.) indicating the gradual decrease of this pesticide in mussels and seawater although the sampling stations (points) were not the same. Aldrin and endrin levels in Karystos samples are surprisingly higher than the levels in Villeneuve's report (which were less than $1 \mathrm{ng} \mathrm{g}^{-1}$ dry wt for aldrin and less than $2.3 \mathrm{ng} \mathrm{g}^{-1}$ dry wt for endrin), indicating the persistent character of these two pesticides in the specific seawater sampling point. 
A variety of scientific efforts have also been extensively carried out in Mediterranean coastal waters near Alexandria, Egypt (Barakat, A.O. 2004). In seawater aldrin was determined in the range of (10-70 ng/L), dieldrin $(<0.1-5 \mathrm{ng} / \mathrm{L})$ and endrin between $<0.1-53 \mathrm{ng} / \mathrm{L}$. Cyclodiene pesticides (aldrin, endrin, dieldrin) concentrations were also detected in bivalves (Donax sp) in the same study below $2 \mathrm{ng} \mathrm{g}^{-1}$ ww. Similar conclusions in this report were derived for fish and aquatic birds. Another scientific research which was conducted by Kucuksezgin (Kucuksezgin et. al 2001) in Eastern Mediterranean (Aegean Sea) revealed the levels of aldrin in red mullet. The levels of aldrin varied between 0.10 and $0.61 \mathrm{ng} \mathrm{g}^{-1}$ dry wt. It must also be reported the large survey conducted in United States (US) concerning the chemicals concentrations in mussels and oysters which were collected along US and updates until 2003 (O'Connor, T.P., Lauenstein, G.G. 2006).

The findings of this research indicate the need for an expanded survey regarding Evia Island which is one of the largest islands of the Mediterranean basin in order to assess in depth the presence or absence of a variety of pesticides which were used in the past or are administered nowadays near to Evias' coastal areas. The high levels of cyclodienes detected constitutes an intriguing target for scientists implemented in toxicology or aquatic environmental studies in order to control the pollution and inform the population involved in fishing or live to adjacent coastal areas (Carreño et. al 2007).

\section{Conclusions}

In this report it was developed a new analytical method for the detection of six organochlorine pesticides in mussels whose origin is Evia Island, Greece. The results of this research showed the presence of residues of aldrin, endrin and endosulfan sulfate although these pesticides are banned. By MASE technique higher concentrations of the identified pesticides were obtained than with the typical Soxhlet. The persistence of organochlorines in the aquatic environment raises problems of chronic toxicity to humans who are frequently exposed to these contaminants, either by bivalves or fish-related dietary intake or by work-related exposure. Thus, repetitive and continuous examination and analysis of these bivalves and other marine organisms is required in order to assess their contamination levels and control with safety the subsequent provision to humans.

\section{References}

Barakat, A.O. (2004). Assessment of persistent toxic substances in the environment of Egypt. Environment International, 30, 309-322.

Batzios, C., Angelidis, P., Papapanagiotou, E. P., Moutopoulos, D. K., Anastasiadou, C., Chrisopolitou, V. (2004). Greek consumers image of the cultured mussel market. Aquaculture International, 12, 239-257.

Carreño, J., Rivas, A., Granada, A., Lopez-Espinosa, M.J., Mariscal, M., Olea, N., Olea-Serrano, F. (2007). Exposure of young men to organochlorine pestisides in Southern Spain. Environmental Research., 103, 55-61.

Ciminiello, P., Dell' Aversano, C., Fattorusso, E., Forino, M., Magno, S., Santelia, F., Tsoukatou, M. (2006). Investigation of the toxin profile of Greek mussels Mytilus galloprovincialis by liquid chromatography-mass spectrometry. Toxicon, 47, 174-181.

Eduljee, G..H. Budget and source inventories: issues and challenges. In: Harrad, S. (Ed.) Persistent Organic Pollution: Environmental Behaviour and Pathways for Human Exposure. Kluwer Academic Publishers, London, pp. 1-28.

García, I., Ignacio, M., Mouteira, A., Cobas, J., Carro, M. (2008). Assisted solvent extraction and ion-trap tandem mass spectrometry for the determination of polychlorinated biphenyls in mussels. Comparison with other extraction techniques. Analytical Bioanalytical Chemistry, 390, 729-737.

Kannan, K.., Tanabe, S., Williams, R.J., \& Tatsukawa, R. (1994). Persistant organochlorine residues in foodstuffs from Australia, Papua New Guinea and the Solomon Islands: contamination levels and human dietary exposure. Science of the Total. Environment, 153, 29-49.

Khaled, A., El Nemr, A., Said, T.O., El-Sikaily, A., Abd-Alla, A.M.A. (2004). Polychlorinated Biphenyls and chlorinated pesticides in mussels from the Egyptian Red Sea Coast. Chemosphere, 54, 1407-1412.

Kucuksezgin, F., Altay, O., Uluturhan, E., Kontas, A. (2001). Trace metal and organochlorine residue levels in red mullet (Mullus Barbatus) from the Eastern Aegean, Turkey. Water Research, 35, 2327-2332.

Kurt, P.B., Ozkoc, H.B. (2004). A survey to determine levels of chlorinated pesticides and PCBs in mussels and seawater from the mid Black Sea coast of Turkey Marine Pollution. Bulletin, 48, 1076-1083.

O'Connor, T.P.; Lauenstein, G.G. (2006). Trends in chemical concentrations in mussels and oysters collected along the US coast: Update to 2003. Marine Environmental Research 62, 261-285.

Ozkoc, H.B., Bakan, G.., Ariman, S. (2007). Distribution and bioaccumulation of organochlorine pesticides along the Black Sea coast. Environmental Geochemistry and Health, 29, 59-68. 
Parimi, S., Meinke, L.J., French, B.W., Chandler, L.D., Siegfried, B.D. (2006). Stability and persistence of aldrin and methyl-parathion resistance in western corn rootworm populations (coleoptera: chrysomelidae). Crop Protection, 25, 269-274.

Perugini, M., Cavaliere, M., Giammarino, A., Mazzone, P., Olivieri, V., Amorena, M. (2004). Levels of polychlorinated biphenyls and organochlorine pesticides in some edible marine organisms from the Central Adriatic Sea. Chemosphere, 57, 391-400.

Richardson B.J., Mak, E., De Luca-Abbott, S.B., Martin, M., McCellan, K., Lam, P.K.S. (2008). Antioxidant responses to polycyclic aromatic hydrocarbons and organochlorine pesticides in green-lipped mussels (Perna Viridis): Do mussels "integrate" biomarker responses? Marine Pollution. Bulletin, 57, 503-514.

Villeneuve, J.P., Carvalho, F.P., Fowler, S.W., Cattini, C. (1999). Levels of PCBs, chlorinated pesticides and petroleum hydrocarbons in mussels from the NW Mediterranean Coast: comparison of concentrations in 1973/1974 and 1988/1989. Science of the Total. Environment., 237/238, 57-65.

Vlahogianni, T., Dassenakis, M., Scoullos, M. J., Valavanidis, A. (2007). Integrated use of biomarkers (superoxide bismutase, catalase and lipid peroxidation) in mussels for assessing heavy metals' pollution in coastal areas from the Saronikos Gulf of Greece. Marine Pollution Bulletin, 54, 1361-1371.

Table 1. Calibration data, concentration range and linearity of the studied OCs

\begin{tabular}{|c|c|c|c|}
\hline OCPs & Equation & Range $(\mu \mathrm{g} / \mathrm{mL})$ & Linearity $\left(\mathrm{r}^{2}\right)$ \\
\hline aldrin & $\mathrm{y}=1354925 \mathrm{x}+8719$ & $0.02-0.10$ & $>0.993$ \\
\hline endrin & $\mathrm{y}=319268 \mathrm{x}+30752$ & $0.02-0.20$ & $>0.999$ \\
\hline dieldrin & $\mathrm{y}=92467 \mathrm{x}-+2555$ & $0.20-1.10$ & $>0.997$ \\
\hline$\alpha$-endosulfan & $\mathrm{y}=63023 \mathrm{x}+3192$ & $0.27-1.20$ & $>0.999$ \\
\hline$\beta$-endosulfan & $\mathrm{y}=43495 \mathrm{x}+1344$ & $0.10-1.00$ & $>0.999$ \\
\hline endosulfan sulfate & $\mathrm{y}=73969 \mathrm{x}-22094$ & $0.50-2.00$ & $>095$ \\
\hline
\end{tabular}

Table 2. Retention times for the OCs, limits of detection and quantification (LOD, LOQ) and selected ions of the studied OCs

\begin{tabular}{|c|c|c|c|c|}
\hline OCs & $t_{\mathrm{R}(\mathrm{min})}$ & $\mathrm{LOD}^{\mathrm{a}}$ & $\mathrm{LOQ}^{\mathrm{a}}$ & $\mathrm{m} / z$ \\
\hline aldrin & 24.28 & 0.014 & 0.044 & $\begin{array}{c}66,79,91,263, \\
265,293\end{array}$ \\
\hline endrin & 30.58 & 0.068 & 0.205 & $\begin{array}{c}67,79,81,82, \\
263,281,317, \\
345\end{array}$ \\
\hline Dieldrin & 29.74 & 0.069 & 0.212 & $\begin{array}{c}79,263,265, \\
277\end{array}$ \\
\hline$\alpha$-endosulfan & 28.55 & 0.042 & 0.126 & $\begin{array}{c}207,237,241, \\
339\end{array}$ \\
\hline$\beta$-endosulfan & 30.99 & 0.018 & 0.054 & $195,237,339$ \\
\hline $\begin{array}{c}\text { endosulfan } \\
\text { sulfate }\end{array}$ & 32.25 & 0.164 & 0.497 & $272,274,387$ \\
\hline
\end{tabular}


Table 3. Results of the precision for the proposed method of organochlorine pesticides in mussels samples

\begin{tabular}{cccc}
\hline Pesticides & Spiking level $^{\mathrm{a}}$ & $\begin{array}{c}\text { Intra-day precision } \\
\text { (R.S.D.\%) }\end{array}$ & $\begin{array}{c}\text { Inter-day precision } \\
\text { (R.S.D.\%) }\end{array}$ \\
\hline aldrin & 0.05 & 8.1 & 8.8 \\
endrin & 0.10 & 5.6 & 6.2 \\
dieldrin & 0.60 & 6.5 & 6.9 \\
$\alpha$-endosulfan & 0.70 & 9.2 & 9.6 \\
$\beta$-endosulfan & 0.55 & 4.8 & 5.3 \\
Endosulfan sulfate & 1.10 & 9.1 & 11.1 \\
\hline
\end{tabular}

${ }^{\mathrm{a}}(\mu \mathrm{g} / \mathrm{mL})$

Table 4. Pesticides detected and the respective concentrations

\begin{tabular}{|c|c|c|c|c|}
\hline $\mathrm{OCs}$ & Orei & Orei & Karystos & Karystos \\
\hline aldrin & n.d. ${ }^{a}$ & n.d. ${ }^{\mathrm{a}}$ & 0.043 & 0.057 \\
\hline endrin & n.d. ${ }^{\mathrm{a}}$ & n.d. ${ }^{\mathrm{a}}$ & 0.117 & 0.178 \\
\hline Dieldrin & n.d. ${ }^{\mathrm{a}}$ & n.d. ${ }^{\mathrm{c}}$ & n.d. ${ }^{\mathrm{a}}$ & n.d. ${ }^{\mathrm{a}}$ \\
\hline$\alpha$-endosulfan & n.d. ${ }^{\mathrm{a}}$ & n.d. ${ }^{a}$ & n.d. ${ }^{\mathrm{a}}$ & n.d. ${ }^{\mathrm{a}}$ \\
\hline$\beta$-endosulfan & n.d. ${ }^{\mathrm{a}}$ & n.d. ${ }^{\mathrm{a}}$ & n.d. ${ }^{\mathrm{a}}$ & n.d. ${ }^{\mathrm{a}}$ \\
\hline endosulfan & 0.519 & 0.615 & n.d. ${ }^{\mathrm{a}}$ & n.d. ${ }^{\mathrm{a}}$ \\
\hline
\end{tabular}

${ }^{\mathrm{a}}$ not detected; ${ }^{\mathrm{b}}$ concentrations in $(\mu \mathrm{g} / \mathrm{mL}) ;{ }^{\mathrm{c}}$ traces of the compound were detected

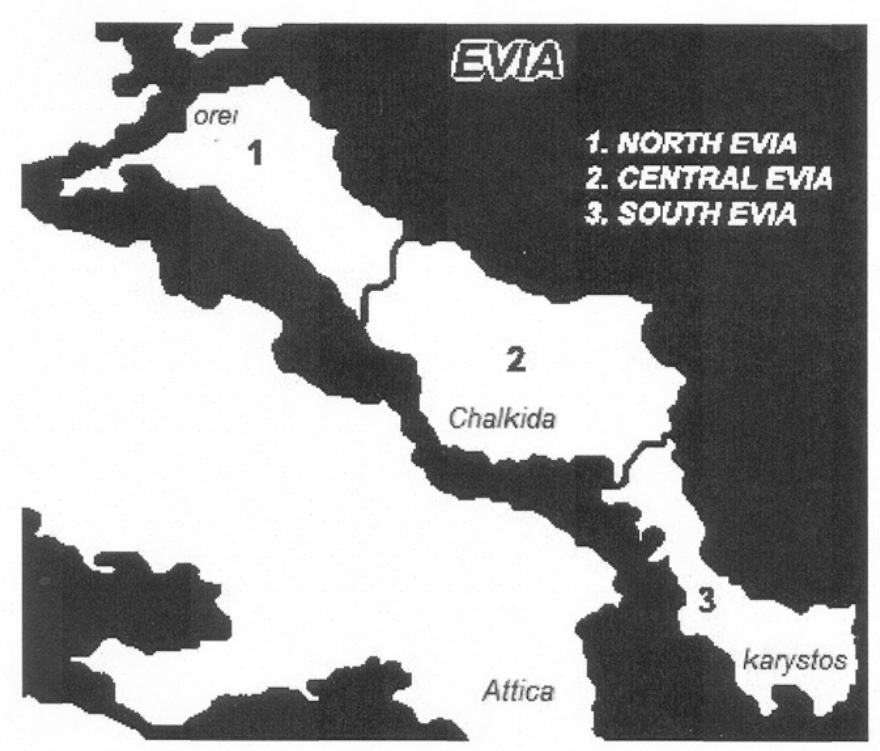

Figure 1. Map with sampling areas 


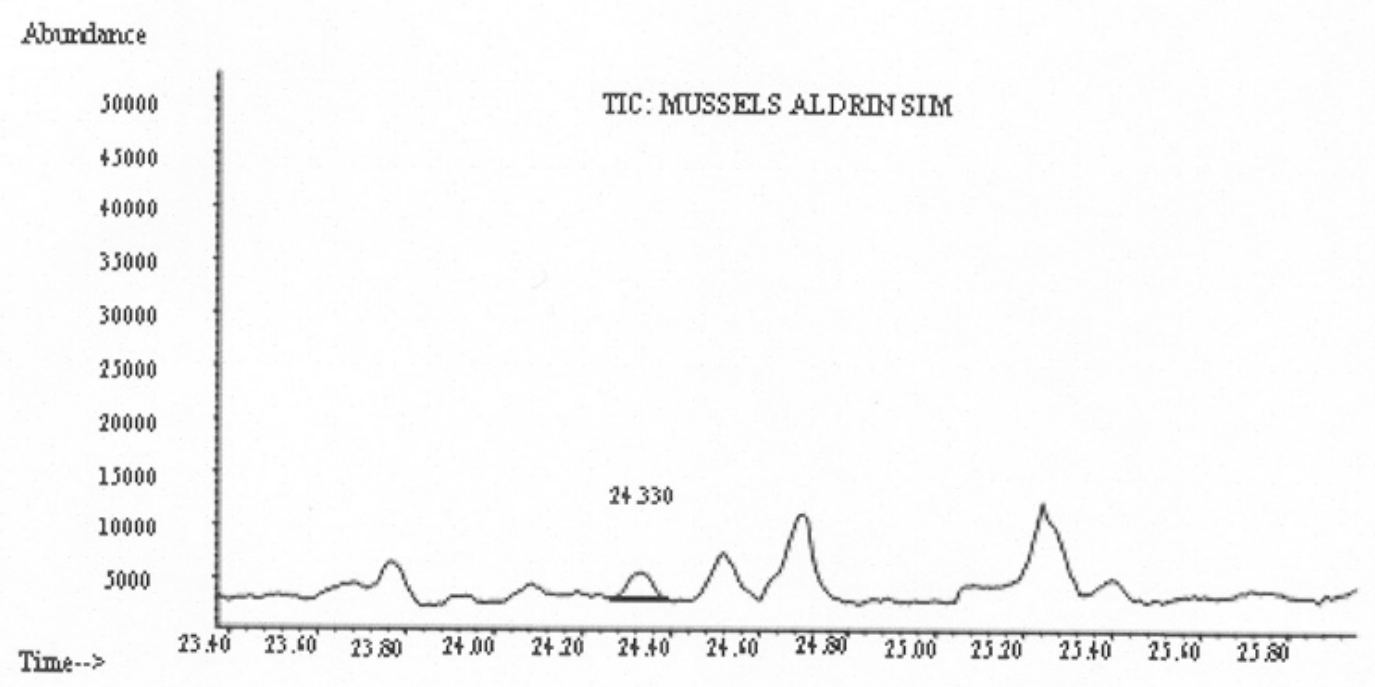

Figure 2. Magnified GC chromatogram of aldrin in real mussel sample of Karystos

\section{Abundance}

$\mathrm{m} / \mathrm{z}->$

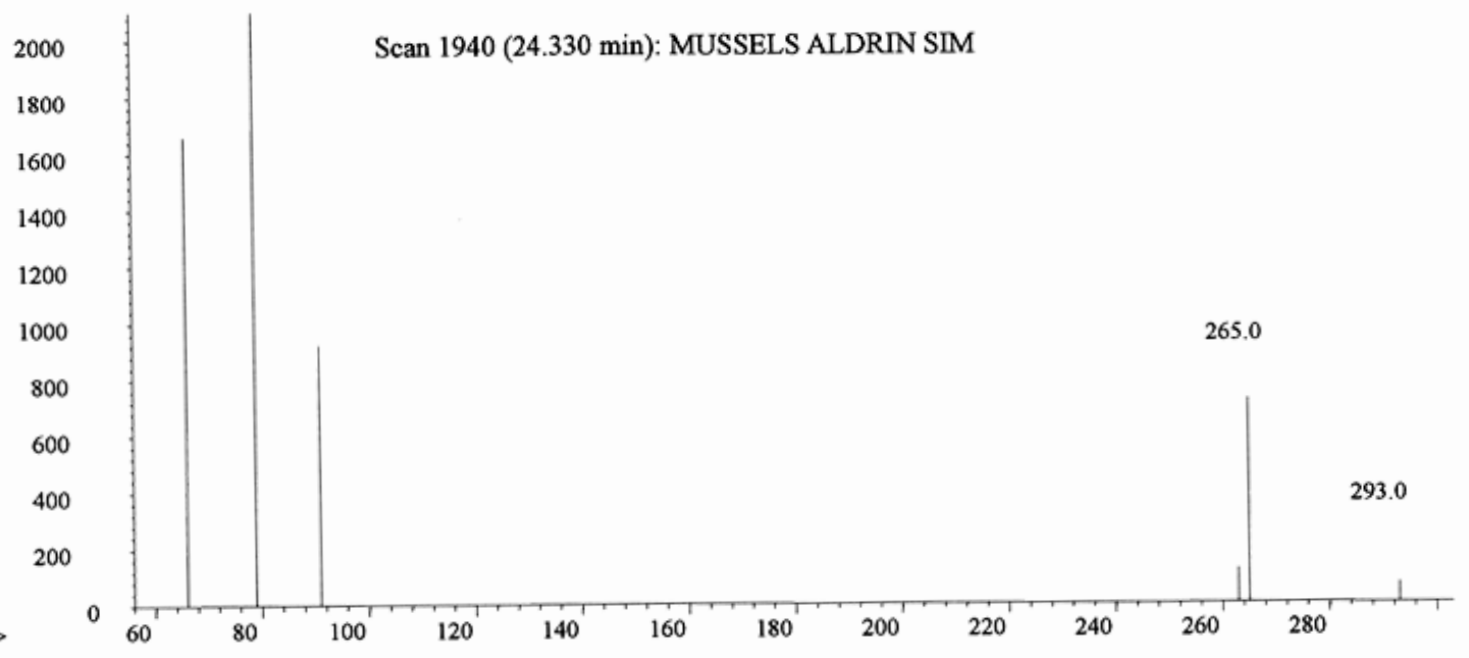

Figure 3. Respective $\mathrm{m} / \mathrm{z}$ ratios for aldrin 


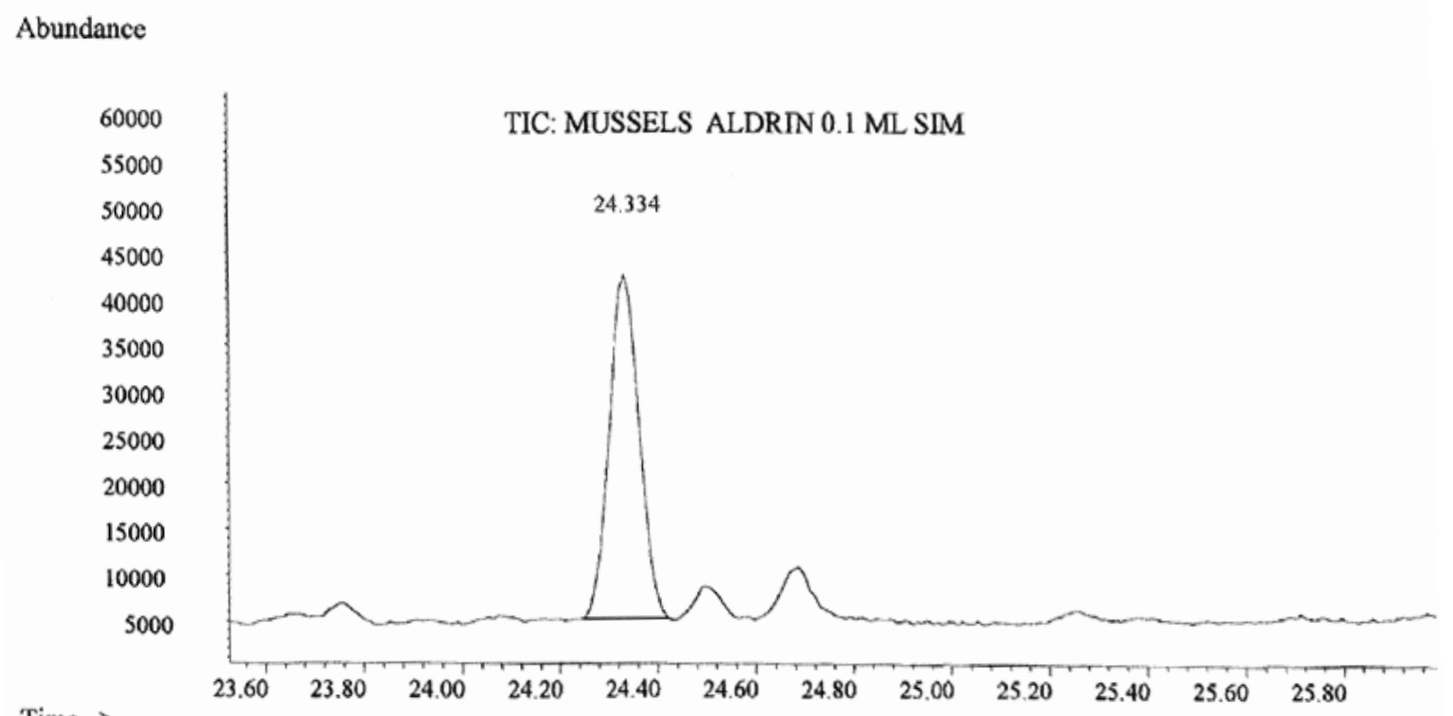

Figure 4. GC chromatogram of spiked with aldrin mussel sample

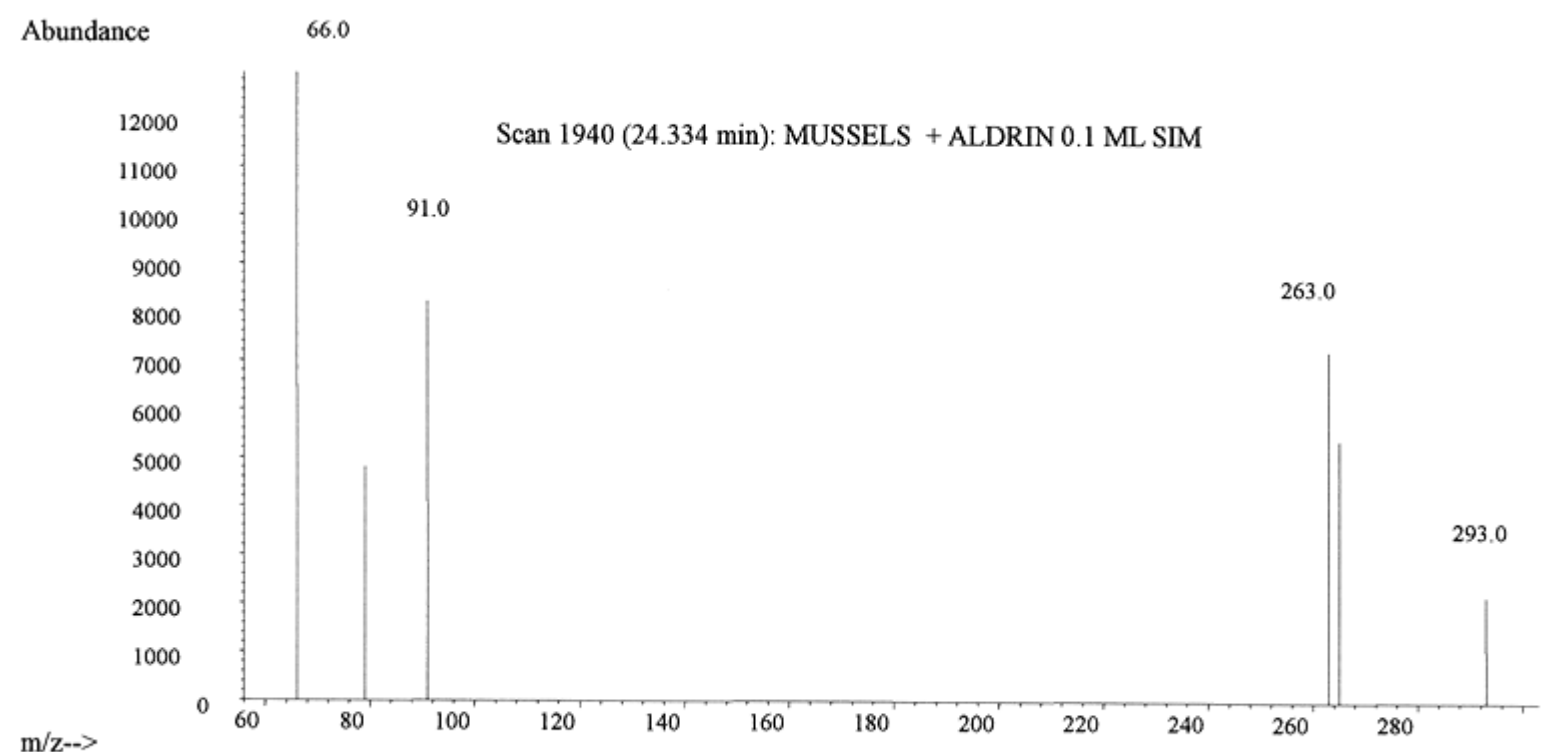

Figure 5. Respective $\mathrm{m} / \mathrm{z}$ ratios for aldrin in the spiked sample 